\title{
The relationship between the form quality of urban housing and the subjective dimensions of place identity (Case study: Zahedan independent housing)
}

La relación entre la calidad de la forma de la vivienda urbana y

las dimensiones subjetivas de la identidad del lugar (Estudio de caso: Zahedan Independent Housing)

Author:

Mehdi Moradgholi ${ }^{1 *}$

Seyed Bagher Hosseini ${ }^{2}$

\section{SCIENTIFIC RESEARCH}

How to cite this paper: Moradgholi M., Hosseini S. B., The relationship between the form quality of urban housing and the subjective dimensions of place identity (Case study : Zahedan independent housing ), ran. Innovaciencia 2020; 8 (1): 1-14.DOI: http:// dx.doi.org/10. 15649/2346075X.1001

\section{Reception date:}

Received: 01 May 2020

Accepted: 01 August 2020

Published: 01 December 2020

Keywords:

Quality of residence, identity, sense of belonging, attachment, Zahedan city.

\section{ABSTRACT}

Background and Aim: Lack of identity and a sense of attachment to housing are some of the hidden problems that enhance long-term feelings of hopelessness in the inhabitants of these environments. The mental- emotional relationship with the environment leads to the increase of the environment life quality. The purpose of this study is to be aware of mental quality of housing in the inhabitants of Zahedan independent housing and to identify the qualitative factors influencing the residents' identity in their residential environment. Materials and Method: The purpose of this study was applied in terms of purpose and survey in terms of method. The research instrument was a researcher-made questionnaire and its validity was confirmed by face validity and its reliability coefficient was 0.78 using Cronbach's alpha test. The statistical population of the study consisted of residents of some areas in Zahedan city and the sample size was 240 that were distributed and completed. Findings and Results: The hypotheses test showed that the variables such as attachment to place, satisfaction, sense of belonging, explain the semantic dimension of place identity and have a significant and positive relationship with the form quality of housing is affected by the cognitive dimensions of residents. The results showed that the mean of individuals' identity to their living space was $1<3.17>5$ which was higher than average. The results indicate that the significance level of the test for all variables except memory is less than $5 \%$ error level. It can be said that the degree of identity of sense of attachment to place and satisfaction varies in different regions, but the degree of memory in different regions is not different. The LSD post hoc test was also applied to investigate whether identity, sense of belonging, attachment to place, and satisfaction were different in the two regions. Finally, the results showed that there was a significant difference in identity in some regions.
1* PhD Student in Architecture - Housing, Iran University of Science and Technology, Tehran, Iran. *Corresponding author: Email: moradgholi mehdi@yahoo.com

2 Ph.D. of Architecture - Faculty of Architecture and Urban Design, Iran University of Science and Technology, Tehran, Iran. Email: hosseini@iust.ac.ir 


\section{INTRODUCTION}

\subsection{Statement of the problem}

Economists and geographers such as Boyer, Savageau, Gabriel, etc. have measured the quality of life using objective variables. On the other hand, social psychologists such as Kamp, Marman, etc. use the quality of life in exchange with subjective concepts such as happiness and pleasure. The emotional relationship between a person and a place depends on his or her satisfaction with the place and how it is evaluated [1] and its degree depends on the person's perception of the place and his or her satisfaction, place quality, and conscious or unconscious, objective or subjective and individual or collective perceptions [2]. As the needs and expectations regarding place are met, the likelihood of developing a more emotional relationship with it increases. [3]. In fact, satisfaction with place is not separate from attachment to place [4].

In some studies, the effective factors on attachment to place have been equal with a sense of social belonging and satisfaction with place, as referred in the study of Benito et al. (2002). Since socialindividual behavior (identity) of society creates the life physical aspects and urban housing creates the physical manifestation of social life, so identity is manifested as determinant of social behavior. However, for the identity of urban housing, on which context, the identity factors can be renovated? When the identity and properties of culture are recognized and as we become partially acquainted with the values of that culture, the choices made by that culture from among the various types of housing to be able to respond simultaneously to physical and cultural variables become obvious [5] Hence, As mentioned above, house is not a merely materialistic object. The social culture is the main factor in the structure of the way of life, and the physical form of houses and dwellings can be considered a physical embodiment of the ideal environment [6]. The concept of home, as a physical form, does not rest on the basis of the organization of interior spaces, but rather meaning is of great importance in its design. In everyday life, "meaning" lies in the use of spaces. Places have meaning and home is the main place of daily human activity [7].

\subsection{Significance of study}

In the studies conducted in Iran, a similar trend in reducing the role of space, meaning, and personality is observed in identifying contemporary homes from the 40 s onwards. The process of eliminating space and neglecting the creative organization of space in accordance with the lifestyle of contemporary residential units in Iran has been faster, affecting the concept of housing and residence. The phenomenon of mass housing is widespread in many cities across the country. This policy is intended to provide housing for the people who own it, and the concept of home has departed from what has existed for thousands of years in human culture, and the home quality in this approach is not discussed. While in many other societies, based on the lifestyle changes, the search for appropriate solutions has led to other solutions - other than what have occupied our cities today.

\subsection{Research questions}

The main question of this study is what factors influence the formation of mental quality of place identity and how is it related to housing form?

The following questions are explained to clarify the dimensions of the main research question:

- What is the significant relationship between residents' identity and type of housing and what is the role of housing plan in this regard?

- In the two identical types of housing, is there a significant difference between the residents' identity and what is the role of the cognitive factors and the mental structure of the residents in this regard?

\subsection{Research Purposes}

The main purpose of the research is to improve the quality of housing in urban housing in order to achieve the identity housing model. 
At lower levels, the purpose of this study is to: Improve the quality of life in housing by taking into account the factors of sense of place and emotional relationship with place of residence.

Achieve a qualitative process for selecting urban housing types and plans, before final design.

\subsection{Research hypotheses}

The main hypothesis is that the degree of identity in independent housing is higher than that of an apartment and has a significant relationship with residents' lifestyle and housing form.

Identity levels in the selected neighborhoods have a significant relationship with each other. Identity is more related to culture and family structure (gender role) than urban context structure.

- The form quality of housing has a different effect on the identity and gender role of residents in men and women.
- The level of identity of the residents and each of its dimensions varies significantly across regions.

\section{THEORETICAL BASICS OF RESEARCH}

Quality of life means having the resources necessary to meet needs, desires, participate in activities, selfesteem, and compare satisfaction between yourself and others. It is defined by the World Health Organization as: An individual's perception of living conditions in relation to the culture and value system in which they live and is related to their goals, expectations, standards and attitudes. [9]. As the concept of quality has both objective and subjective dimensions, two completely separate types of indicators are needed to measure it: first, objective indicators that describe people's living environments. Such as housing facilities, public and private open spaces, and second, subjective indicators that describe how people perceive and evaluate their environment, such as the possibility of social relationships or the perception of beauty in the environment [8].

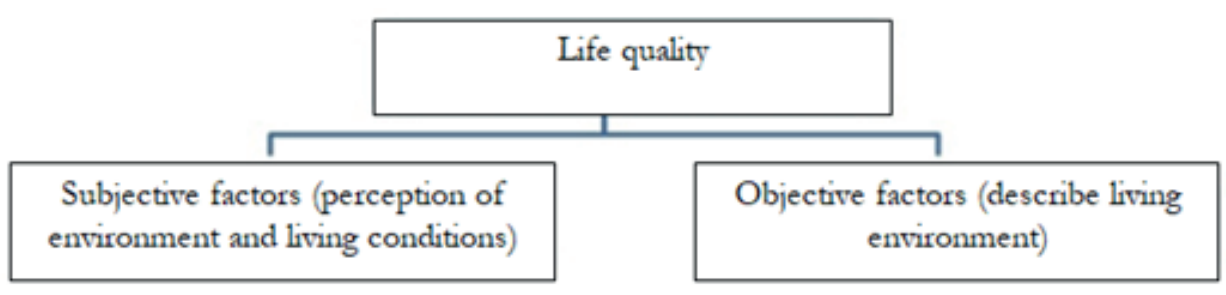

Chart 1- Dimensions of quality of life (Reference: Author)

The quality of urban life first refers to the extent to which residential areas respond to the basic needs of human being. This quality reflects the overall social, physical, and cultural characteristics of the environment in an area that is used as a measure to assess the extent to which a person's mental, psychological and material needs are met [10]. Social indicators to promote community cohesion as a concept seek to maintain and stabilize the social and cultural components of the society in conjunction with environmental dimensions and the promotion of quality of life [11]. The social index consists of several factors, the most important of which are social participation, social cohesion and social security [12]. 
Table 1: Social criteria for quality of life (Source: Author)

\begin{tabular}{ll}
\hline Field & Social index \\
\hline $\begin{array}{l}\text { Establish social links of people with environment, reduce social stress among the residents, } \\
\text { direct engagement of people in determining and defining their living environment, increase } \\
\text { the social responsibility, freedom and decision making right for the residents, complete } \\
\text { participation of residents in local actions. }\end{array}$ & $\begin{array}{l}\text { participation } \\
\end{array}$ \\
$\begin{array}{l}\text { Establish value, trust and collective norms, recover identity and the attempt to increase } \\
\text { sense of place of residents to the township, preperation to use the urban priorities and }\end{array}$ & Social cohesion \\
$\begin{array}{l}\text { deepening the urban culture for the informal inhabitants, social cohesion as a basis for } \\
\text { collective identity }\end{array}$ & \\
$\begin{array}{l}\text { Define the human domain, observe private and public areas by the residents, getting rid of } \\
\text { fear, risk and safety of any threat, tendnecy to be present in environemnt, increasing }\end{array}$ & Social security \\
competence & \\
\hline
\end{tabular}

"Environmental quality has been used as an indicator used to measure the degree of environment that is appropriate for human life" [13]. Experts of different disciplines have done various researches in this area and especially on the quality of the residential environment in which two different approaches can generally be observed: 1 - An independent concept that provides an overview of the quality of the components of an environment but it has more than its sum of effects on the overall perception of the place, 2) its definition of the more general concept of quality of life, which reflects all aspects of one's sense of well-being, including all the variables that affect human satisfaction [14].

\subsection{Relationship between the quality of urban environments with place and perception}

It should be noted that spatial qualities are topological attributes that do not depend on the dimensions of the constituents of the space and the small distance between the components of a space, but rather depend on the relationships arising from the relationships of the components, such as how the elements interact, their order, and so on. [15]. To address the concept of perception, it is necessary to first examine the concept of territory and its relation to perception.

The sense of territory search comes from the sense of attachment and belonging to place. The territory reinforces a sense of distinctiveness, privacy, and a sense of individual identity. The need for territory can be explained in terms of regulating the privacy of self and others [16] According to Altman, the territory depends on four factors: duration of living in a place, perceptual effects on the resident and others in creating a sense of ownership, extent and personal value of the place, the extent defensibility of the place in case of invasion to the territory. The concept of territory is defined in phenomenology in relation to the concept of place, which leads to the definition of the concept of inside and outside of architecture (although it is necessary to mention that the definition of territory differs depending on different cultures). The discussion of the concept of territory requires understanding how human perceptions of different spaces and places are perceived in the form of the perception psychology.

Ittelson (1978) identifies four cognitive, emotional, interpretive, and evaluative dimensions of perception and believes that these four dimensions operate simultaneously [17]: The most important point in explaining perception is the environmental perception issue. The environment becomes architecture once people understand it, understanding it is different from knowing that is based on physical signs [18]. Bourassa (1991) identified two types of perceptions, namely biological and cultural perceptions. In addition, both scientific and philosophical perceptions can be categorized in this view. Scientific perception includes physical elements (light, color, etc.), bright elements (such as sun and moon) and geometry. 
Philosophical perception deals with aesthetics (e.g. beauty, remembrance, and comfort) [18]. Researches are divided into two categories: visual perception and social perception in environment perception [19]:

Table 2: Types of Environmental Perceptions (Source: Author)

\begin{tabular}{lll}
\hline Types of view perception & Date & Researcher \\
\hline Biological perception/cultural perception & 1991 & Bourassa \\
Scientific perception/philosophical perception & 2002 & Makhzoumi \\
Visual perception/social perception & 2011 & Cassatella \& Peano \\
\hline
\end{tabular}

Rapporte, in his "Theory of Perception (1977)", believes that environmental perception has three indivisible elements. These three elements form an indistinguishable set from the view of Rapport that includes cognitive-evaluation perception. His model has filters in the perception process. He introduces two types of filters [20]:
- Information filters (which are objective in nature and consist of cultural mental images based on information, knowledge, standards of living and education);

- Attitude filters (they are subjective in nature and based on personal perceptions based on the individual value system).

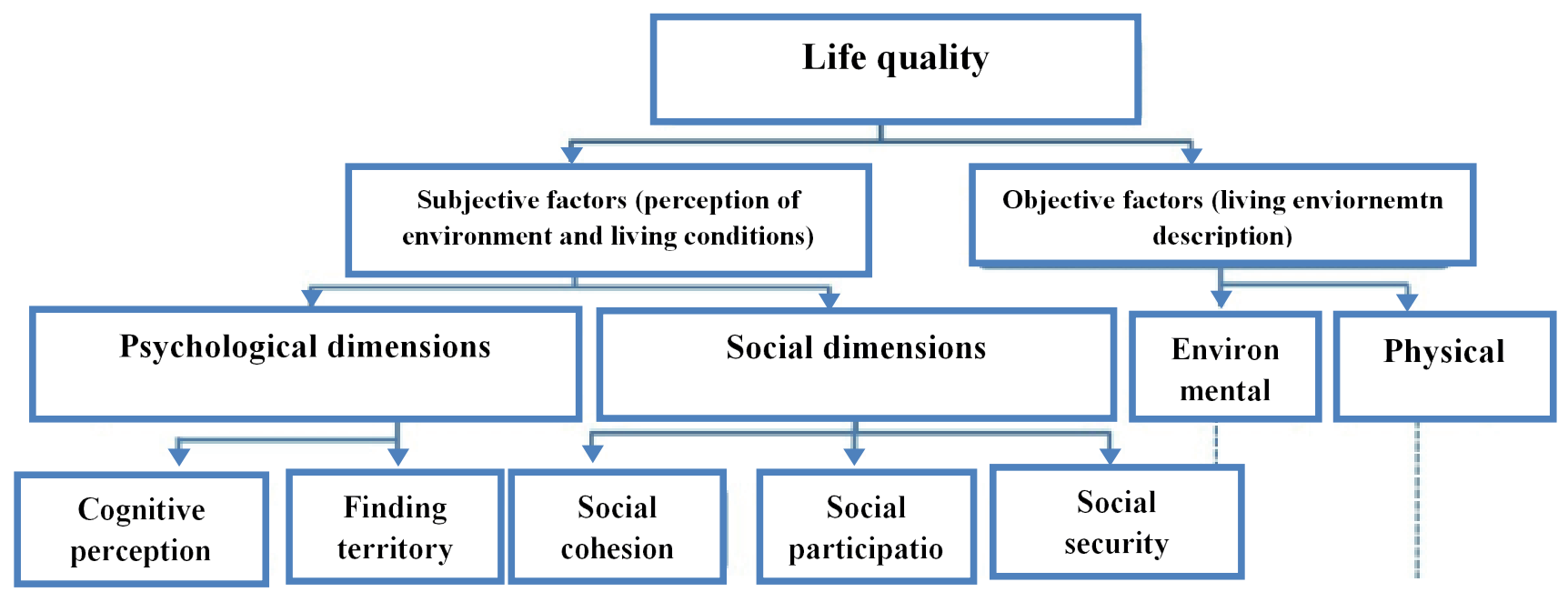

Chart 2- Dimensions of quality of life in residential environment (Reference: Author)

2.2. The relationship between objective and subjective quality in architecture with residential satisfaction

According to the relevant literature, residential satisfaction results from a wide range of perceived subjective and objective conditions. [21]. Researchers agree that the gap between understanding the real environment and wishing for the environment determines the degree of satisfaction or dissatisfaction. In other words, residential satisfaction can determine the extent to which people find the environment responsive to their needs and goals. Understanding the environment depends on objects and the environment and how residents see them [22].

Some researchers, such as Galster, Hesser, Marans, etc. have discussed about the theory of actual -aspirational in residential satisfaction and one's 
ultimate recognition of one's environment depends on the followings: the objectivity of environment, the subjective understanding of environmental variables, and background characters. This framework can be used to estimate residential, neighborhood, and community units [22]. Galster has defined this concept as the gap between residents' desires and needs and the current reality of their residential environment. [14].

\subsection{Relationship between satisfaction with place and attachment to place}

The emotional relationship between a person and a place depends on his or her satisfaction with the place and how it is assessed [1] and its extent depends on the person's perception of the place and his / her satisfaction with it, the quality of the place and its security (including economic, social and physical security) that such perceptions are conscious or unconscious, objective or subjective, individual or collective and result in security of place, maintenance, development, and preservation [2]. This is not only necessary but most likely to occur when human needs and expectations are met. Therefore, one of the most important aspects to consider in this regard is the degree of satisfaction with the place. As the needs and expectations are met, the likelihood of developing a more emotional relationship with it increases. [3] Satisfaction with place is not in fact separate from attachment to place [4]. In some studies, the effective factors on attachment to place have been equal with a sense of social belonging and satisfaction with place, as referred in the study of Benito et al. (1999). The theory of attachment to place implies that individuals develop their attachment to place based on their expectations based on their previous experiences and cognitive process and their satisfaction with the place depends on this knowledge [23].

\subsection{Relationship between attachment to place and sense of place identity}

In general, there are two dominant views in explaining attachment dimensions to the place:
The first view considers place attachment including both functional and emotional dimensions; in fact, the functional dimension refers to the fulfillment of individual needs and goals [24], which are based on the quality of place in responding to the users in comparison to other similar places. This dimension depends on one's previous experiences of similar locations and places [25] proximity to the place and activity patterns in it [26]. Also, the emotional dimension is related to the sensory interaction between human and place and its role in individual identity [24] and "refers to dimensions of self that indicate one's identity in relation to the physical place [27]. This dimension has been described by various individuals such as Kyle, William and his colleagues, Low \& Altman, and Hialgo \& Hernanez, as social belonging based on the meaning of place based on shared experiences with others and the role of memories in it [28].

The second view, the attachment to place is defined by two dimensions of place dependence and place identity [29]. Location dependency is in fact the ability to respond to a person's needs and is in fact the opportunities that a place provides to meet his/her needs and goals [30] and that refers to the existence or possibility of participating in specific activities in place [31]. In other words, positive or negative feelings about a place [32] is related to the degree of one's previous experiences of the place [30] and establishes a continuous relationship between the individual and the particular place based on its ability to respond to his activities and goals [33].

On the basis of Lynch's studies, Relph defines place identity as "the identity of a place creates, spatial distinction whose basis is known as a distinct whole"[34]. In fact, the place identity is what people make in their minds about a particular place or the image of that place for them. Dimensions of the 'self' that explain a person's personal identity in relation to the physical place [35] (Proshansky et al. 1983 and Proshansky, 1978) reflect the stored memories and abstract symbols of self and place in the individual [36]. So, place identity is formed based on symbolism (such as place name), time factor, type of experience gained in place, one's sensory and 
psychological achievements in relation to place [36], memories, people's spatial background, indigenous and local dimensions, place quality, and special experiences gained there [34], as people thereby identify themselves with a particular type of habitat and feel based on it [37].

Arousing a sense of place identity is associated with some factors such as: replication of place experience [38], or in other words, the presence and repetition of interactions with place, i.e. the basis of functional dependence on place [39], preference, care [40], social factors and the degree of presence of individuals in that place. In fact, individuals develop place identity by increasing their sense of social belonging [41]. Increasing this sense leads to the responsive and committed behaviors towards the place.

The place identity is "the mental image, the experiences production, thoughts, memories and feelings, and the purposeful interpretation of what is and what should be" [41]. This issue is related to the physical differentiations of place and is a relative topic and is more focused on the activity and meaning of place. In addition, place identity is also a kind of emotional attachment to place based on the symbolic significance of place, as a container of emotions and communication that gives meaning and purpose to one's life [33].

What is unique about the place, or the spirit of the place, is built into the identity that can be stable despite the change in the elements. Central to this quality is the factor that Proshansky calls the spatial past of the individual. "This past includes the types of locations and characteristics that contribute as a means of meeting one's cultural, social, psychological, and physiological needs" [27]. He classifies the dimensions of place identity into three groups:

a. Descriptive-cognitive dimension: This dimension relates to one's conscious, unconscious thoughts, memories, thoughts, and beliefs about the physical features of the place;

b. Evaluation-emotional dimension: This dimension is related to the kind of feeling and preference regarding the content of the place such as color, style, form, sounds, dimensions, mode of lighting and other such factors.

c. Place and needs of the individual: This dimension is explained by the role of the individual and the set of expectations, beliefs, feelings, ideas, and implications that result from the place (ibid).

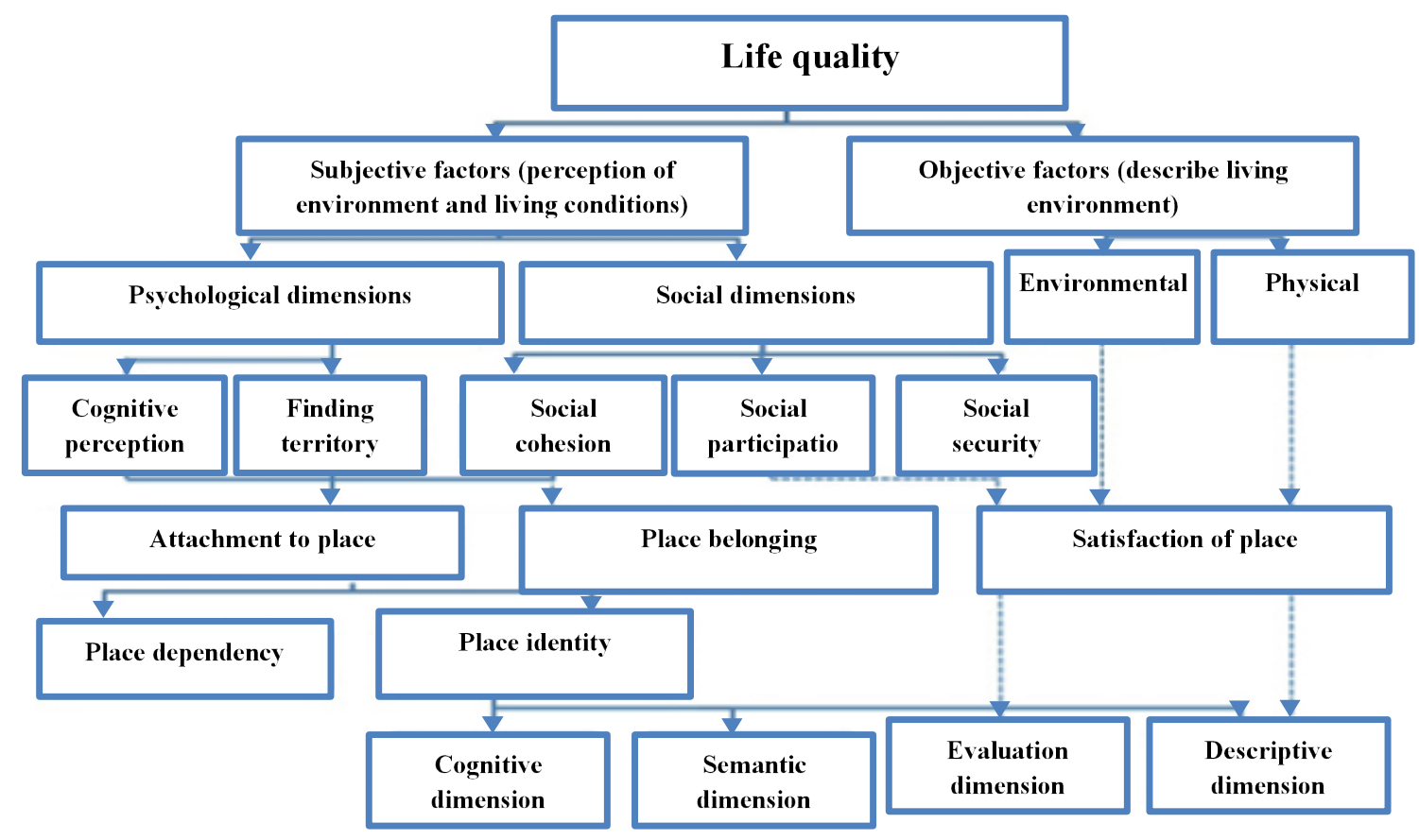

Chart 3- Explain the place identity and its relation to quality factors in residential environment (Reference: Author) 


\section{RESEARCH AREA}

Zahedan city, with an area of 36581 square kilometers, is located in the north of Sistan and
Baluchestan province, in Baluchistan with hot and dry climate. According to the general housing census in 2016 , the population of the city was 672 '589 (in 168 '480 households).
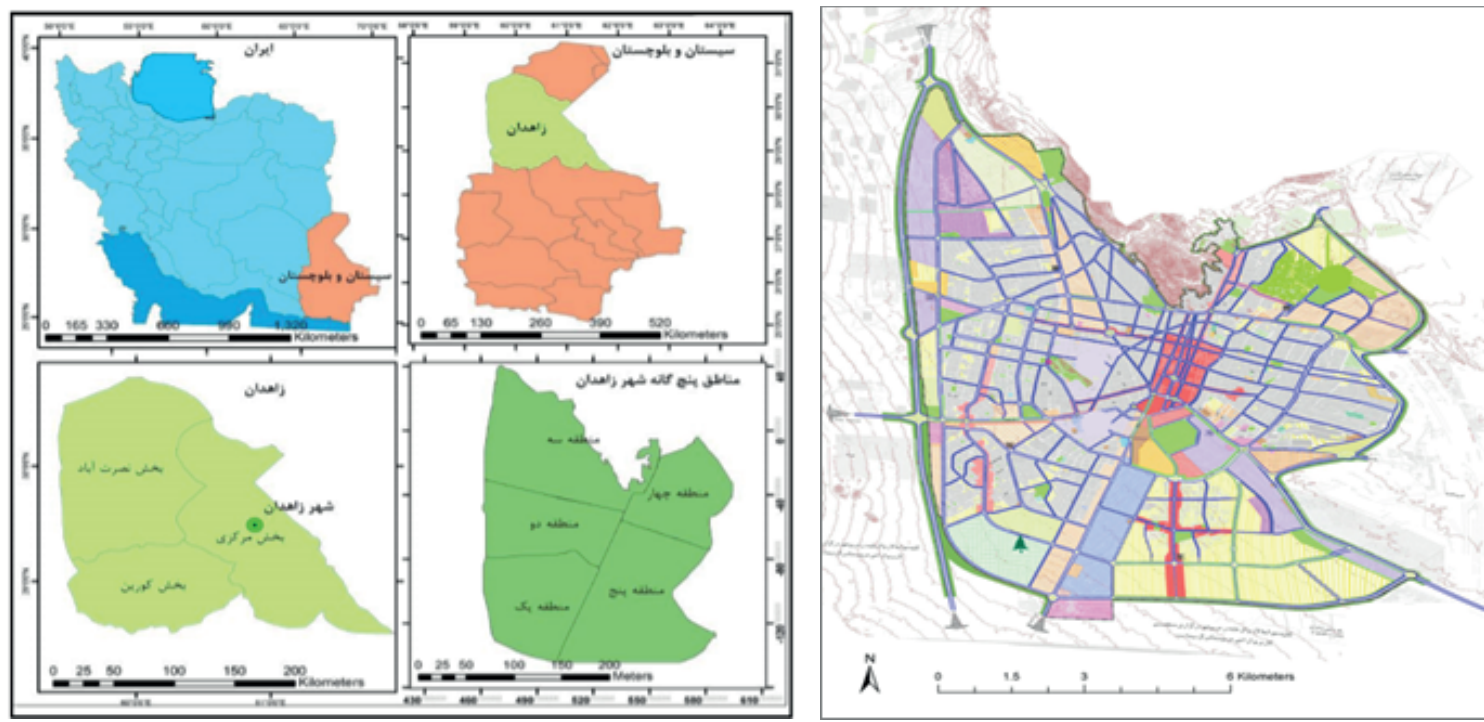

Image 1: Zahedan Map, Source (Statistical Calender of Sistan and Baluchestan Province, 2017)

\subsection{Recognize the form structure of the housing of the study areas}

The study structure has been selected in six areas of the statistical population that are at the neighborhood unit such as Ghelnbar, Janbazan Gharbi, Koi Quds, Beheshti, Southern Khorramshahr and Karimpur. The type of housing selected is often one-floor and one-unit, with about nine or ten plans being drawn from each study area and questionnaires are developed in these plans or similar dwellings around them. According to the specific cultural structure of Zahedan city, the selection of these six areas, except for the Karimpur and Khorramshahr areas, is often defined in the social classes of employees. It should be noted that the Khorramshahr area belongs to the families of the martyrs, which, is left to the families themselves and this is of great importance in this study to examine the role of gender in identity.
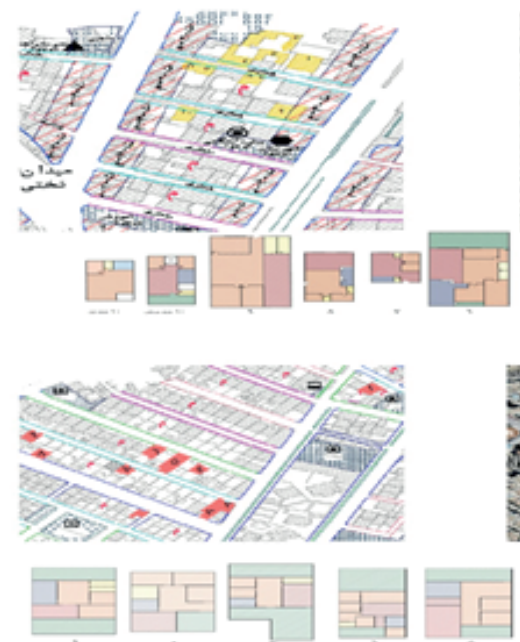
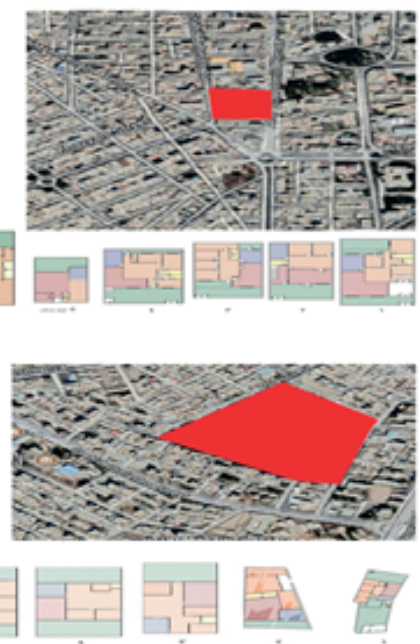
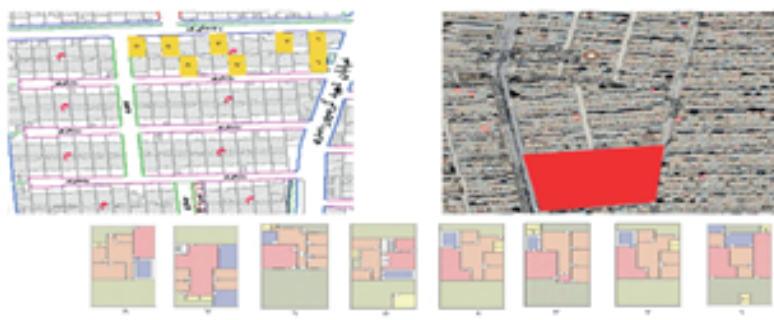

Hen
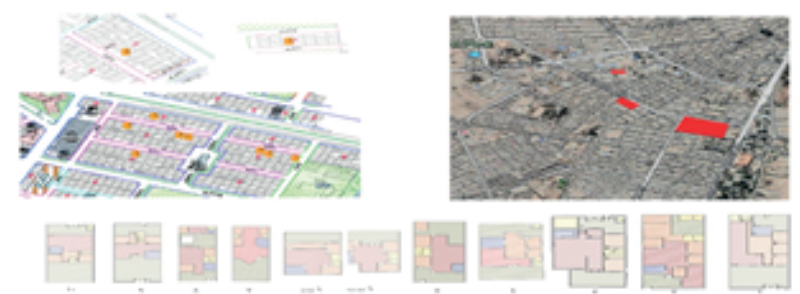

Image 2: Area 1 (Ghalanbar), area 2 (Janbazan Ghabri) left, indicated in Google Aerial Photo and in the detailed design Map of Zahedan with the collected plans, Source: Author 

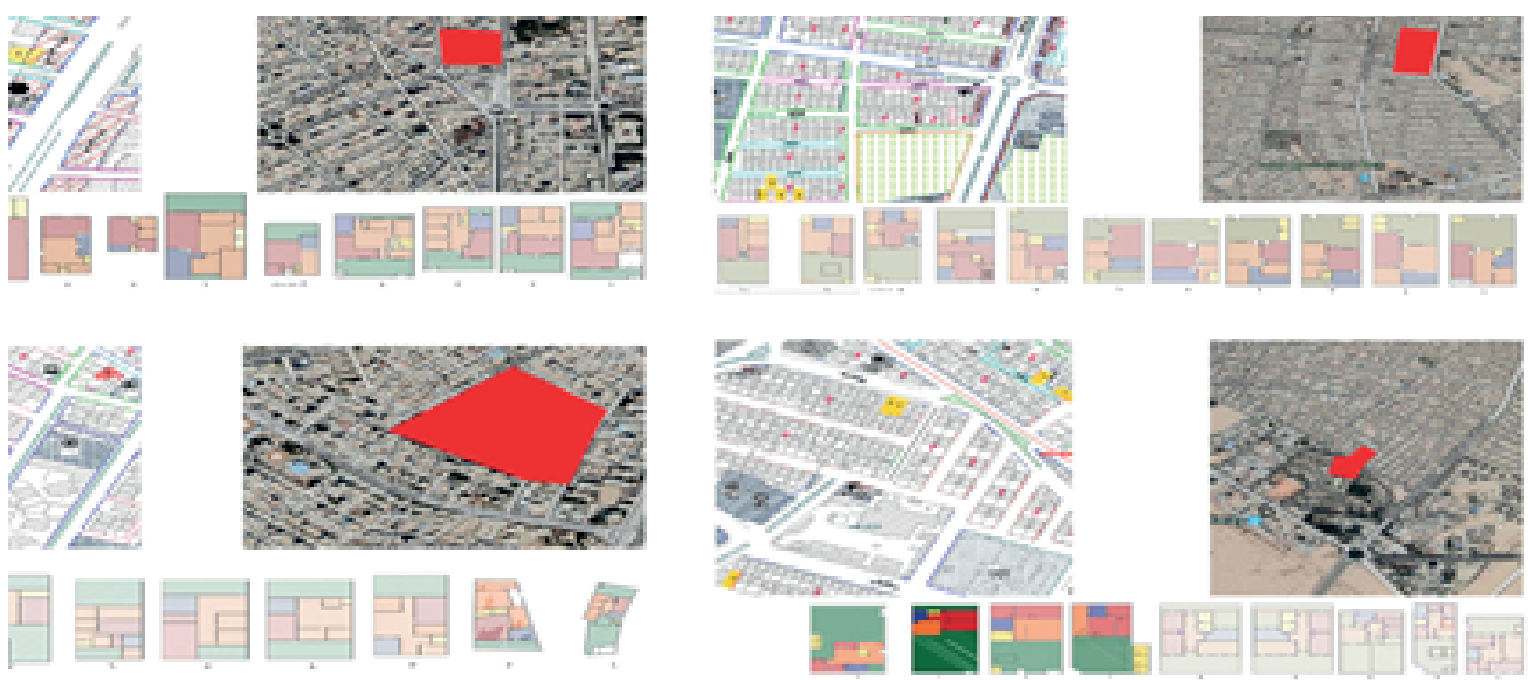

Image 3: Area 3 (Kooye Qods) right, area 4 (Beheshti) left, indicated in Google aerial photo and in Zahedan detailed plan map with the collected plans, Source: Author

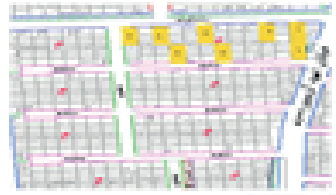

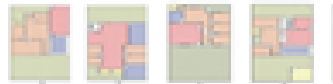
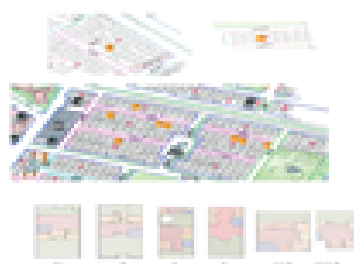
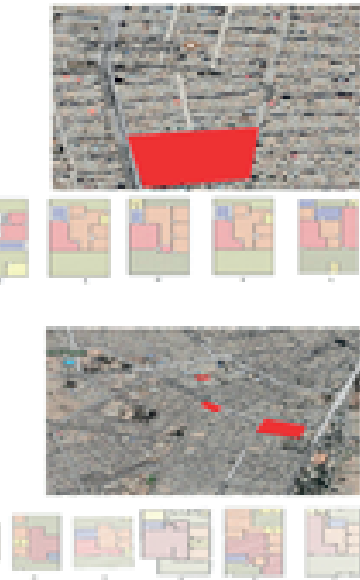
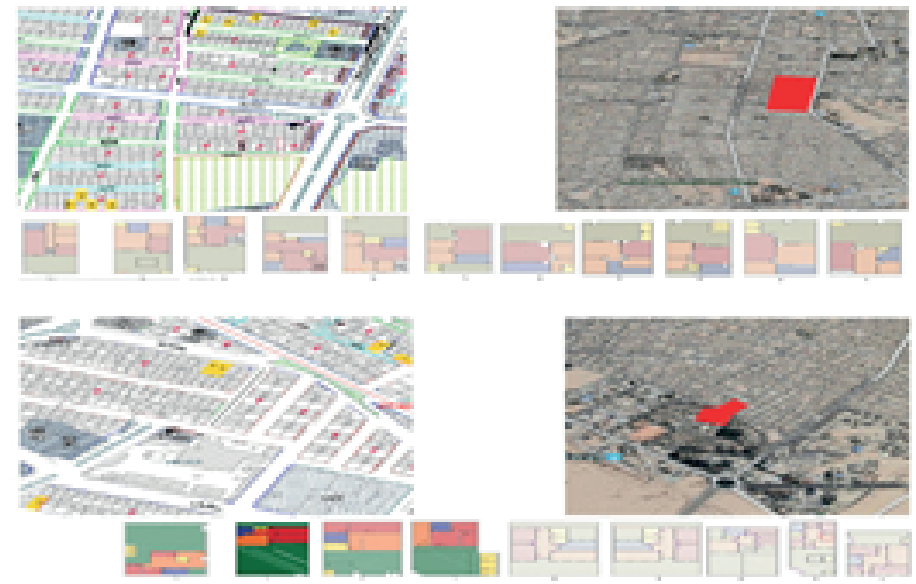

Image 4: Area 5 (Western Khorramshahr) right, Area 6 (Karimpur) left, defined in Google aerial photo and Zahedan detailed Map with collected plans, Source: Author

\section{DATA ANALYSIS}

In this section, the findings of the questionnaire will be analyzed in both descriptive and inferential levels. At first, the characteristics of the statistical sample are expressed at descriptive level. Then, using confirmatory factor analysis, the conceptual model of research is examined and assumptions related to it are tested.

\subsection{Descriptive statistics}

Findings related to the demographic characteristics of the sample showed that $50 \%$ of the sample was male and $50 \%$ was female. $30.6 \%$ of the sample is 15-30 years old, 39.4\% 30-45 years old, 25.6\% -45 years old, 3.3\% 60-75 years old and 1.1\% as 75 -90years old. In terms of education, $7.2 \%$ are below the diploma, $33.3 \%$ diploma, $43.3 \%$ bachelor 
degree, $11.1 \%$ post graduate, and 5.1 percent did not respond. Also, $17.2 \%$ of the sample was in the district $1,20 \%$ in the district $2,10.6 \%$ in the district 3, $20 \%$ in the district $4,15.6 \%$ in district 5 and $16.7 \%$ in the district 6 .

\subsection{Inferential findings}

Descriptive information such as mean and standard deviation of the research variables are calculated and presented in the following table. The results show that the mean of the variables of the research has a suitable level.

Table 3: Mean and standard deviation of the research variables

\begin{tabular}{ccccc}
\hline SD & Mean & Sample size & Component & Variable \\
\hline 0.76 & 3.53 & 180 & Belonging sense & \\
0.62 & 3.47 & 180 & Attachment to place & Identity \\
0.59 & 3.63 & 180 & Satisfaction & \\
0.84 & 3.37 & 180 & Memory & \\
0.62 & 3.80 & 180 & Familiarity and recognition & \\
0.60 & 3.33 & 180 & Legibility and distinction & Form quality of housing \\
0.86 & 3.40 & 180 & Environmental fit & \\
\hline
\end{tabular}

\subsection{Significance of the study data}

When testing the data normality, we test the null hypothesis that the data distribution is normal at the $5 \%$ error level. Therefore, if the test statistic is greater than or equal to 0.05 , then there would be no reason to reject the null hypothesis that the data is normal. In other words, the data distribution will be normal.

Table 4: Kolmogorov-Smirnov test results to determine normal distribution of research data

\begin{tabular}{ccccc}
\hline \multicolumn{2}{c}{ Kolmogorov - Smirnov test } & Component & \multirow{2}{*}{ Main variables } \\
\cline { 1 - 3 } Result & Significance & Statistics & & \\
\cline { 1 - 2 } Normal & $110 / 0$ & $086 / 0$ & Belonging sense & \\
Normal & $096 / 0$ & $109 / 0$ & Attachment to place & \multirow{2}{*}{ Mental dimensions } \\
Normal & $306 / 0$ & $121 / 0$ & Satisfaction & \\
Normal & $212 / 0$ & $128 / 0$ & Memory & \\
Normal & $058 / 0$ & $125 / 0$ & Familiarity and recognition & \\
Normal & $088 / 0$ & $147 / 0$ & Legibility and distinction & Formal quality of housing \\
Normal & $360 / 0$ & $152 / 0$ & Environmental fit & \\
\hline
\end{tabular}

The results of Table 4-6 show that since the significance level of the main variables of the research is greater than 0.05 , the distribution of data is normal and parametric statistics are used for data analysis. Also considering the normality, the structural equation modeling method with covariance-based approach and Amos software can be used.

\subsection{Factor analysis of research variables}

\subsubsection{Confirmatory factor analysis of research variables}

In this study, factor analysis is used both in constructing and validating the questionnaire and in 
testing the assumed factor structure of a theoretical construct. The factor load of all questions is higher than 0.3 , which means that all the questions have good power to explain the components.

\subsubsection{Significance of standard coefficients}

The standard estimation model is presented because it has binary correlation coefficients to allow comparison between indices and dimensions and $\mathrm{T}$ index should be used to determine the significance of these coefficients. The significance numbers model is presented to know whether the relationship between the questionnaire questions and the variables is significant or not. As shown in the following table, all significance numbers of factor loadings and path coefficients of the present model are greater than 1.96, so all factor loadings and path coefficients are significant.

Table 5: Significance coefficients of the research variables measurement model

\begin{tabular}{|c|c|c|c|c|c|c|}
\hline $\begin{array}{l}\text { Signific ance } \\
\text { le vel }\end{array}$ & $\begin{array}{l}\text { Path coefficient } \\
\text { signific ance (C.R) }\end{array}$ & $\begin{array}{l}\text { Standard } \\
\text { error }\end{array}$ & $\begin{array}{l}\text { Coefficients at } \\
\text { non-standard state }\end{array}$ & & & \\
\hline & & & 1.000 & Identity & $<-$ & Belonging \\
\hline .007 & 2. 674 & .163 & .436 & Identity & $<-$ & $\begin{array}{l}\text { Attachment to } \\
\text { place }\end{array}$ \\
\hline .002 & 3.086 & .194 & .598 & Identity & $\begin{array}{l}<- \\
--\end{array}$ & Satisfaction \\
\hline$* * *$ & 3.636 & .255 & .927 & Identity & $<-$ & Memory \\
\hline .002 & 3.111 & .288 & $\begin{array}{l}1.000 \\
.895\end{array}$ & $\begin{array}{l}\text { Form } \\
\text { quality of } \\
\text { housing } \\
\text { Form } \\
\text { quality of } \\
\text { housing }\end{array}$ & $\begin{array}{l}<- \\
-- \\
<- \\
--\end{array}$ & $\begin{array}{l}\text { Familiarity and } \\
\text { recognition } \\
\text { Legibility and } \\
\text { distinction }\end{array}$ \\
\hline
\end{tabular}

\section{CONCLUSION}

9.1-First hypothesis test: The form quality housing is effective on the identity of residents. To test this hypothesis, the research model has two standard coefficients and significance coefficients.

Table 6: Significance coefficients of the research variables measurement model for the first hypothesis

\begin{tabular}{llllll}
\hline $\begin{array}{l}\text { Signific ance } \\
\text { leve1 }\end{array}$ & $\begin{array}{l}\text { Path coefficient } \\
\text { significance (C.R) }\end{array}$ & $\begin{array}{l}\text { Standard } \\
\text { error }\end{array}$ & $\begin{array}{l}\text { Coefficients at nen } \\
\text { standard state }\end{array}$ & \\
\hline$* * *$ & 3.527 & .353 & 1.246 & $\begin{array}{l}\text { Form quality }<- \\
\text { of housing }-\end{array}$ & Identity \\
& & & & & \\
\hline
\end{tabular}

9-3-2- The second hypothesis testing: Residents identity differs from one another in different regions. ANOVA test was used to investigate the differences of residents' identities in different regions. In this test the mean obtained for resident identity is compared between different regions and its results is shown in Table (4-16). 
Table 7: ANOVA test results for resident identity in different regions

\begin{tabular}{llllll}
\hline Signific ance level & F statistics & $\begin{array}{l}\text { Degree of } \\
\text { freedom }\end{array}$ & $\begin{array}{l}\text { Sum of } \\
\text { squares }\end{array}$ & Variable \\
\hline 0.006 & 3.389 & 5 & 3.753 & Intergroup & Identity \\
& & 174 & 38.540 & Intra-group & \\
& & 179 & 42.293 & Total & \\
0.001 & 4.454 & 5 & 11.618 & Inter-group & Belonging \\
& & 174 & 90.769 & Intra-group & \\
& & 179 & 102.386 & Total & \\
0.004 & 5 & 6.414 & Inter-group & Attachment \\
& 3.562 & 174 & 62.666 & Intra-group & to place \\
& & & & & \\
0.004 & & 179 & 69.080 & Total & Satisfaction \\
& 3.565 & 5 & 5.762 & Inter-group & \\
& & 174 & 56.244 & Intra-group & \\
0.975 & & 179 & 62.007 & Total & \\
& & 5 & .595 & Inter-group & Memory \\
& & 174 & 125.703 & Intra-group & \\
& & & & & \\
\hline
\end{tabular}

Table 8: LSD test results for identity

\begin{tabular}{lllll}
\hline Significance level & Standard error & Mean difference & Regions (J) & Regions (I) \\
\hline .846 & .11532 & -.02240 & $\mathrm{p} 2$ & $\mathrm{P} 1$ \\
.285 & .13712 & -.14712 & $\mathrm{p} 3$ & \\
.624 & .11532 & -.05659 & $\mathrm{p} 4$ & \\
.001 & .12270 & $-.43189^{*}$ & $\mathrm{p} 5$ & \\
.147 & .12053 & -.17539 & $\mathrm{p} 6$ & \\
.846 & .11532 & .02240 & $\mathrm{p} 1$ & $\mathrm{P} 2$ \\
.351 & .13345 & -.12472 & $\mathrm{p} 3$ & \\
.758 & .11093 & -.03419 & $\mathrm{p} 4$ & \\
.001 & .11859 & $-.40949^{*}$ & $\mathrm{p} 5$ & \\
.190 & .11634 & -.15299 & $\mathrm{p} 6$ & \\
.285 & .13712 & .14712 & $\mathrm{p} 1$ & $\mathrm{P} 3$ \\
.351 & .13345 & .12472 & $\mathrm{p} 2$ & \\
.498 & .13345 & .09053 & $\mathrm{p} 4$ & \\
.043 & .13989 & $-.28477^{*}$ & $\mathrm{p} 5$ & \\
.838 & .13799 & -.02827 & $\mathrm{p} 6$ & \\
.624 & .11532 & .05659 & $\mathrm{p} 1$ & $\mathrm{P} 4$ \\
.758 & .11093 & .03419 & $\mathrm{p} 2$ & \\
.498 & .13345 & -.09053 & $\mathrm{p} 3$ & \\
.002 & .11859 & $-.37531^{*}$ & $\mathrm{p} 5$ & \\
.309 & .11634 & -.11880 & $\mathrm{p} 6$ & \\
.001 & .12270 & $.43189^{*}$ & $\mathrm{p} 1$ & $\mathrm{P} 5$ \\
.001 & .11859 & $.40949^{*}$ & $\mathrm{p} 2$ & \\
.043 & .13989 & $.28477^{*}$ & $\mathrm{p} 3$ & \\
.002 & .11859 & $.37531^{*}$ & $\mathrm{p} 4$ & \\
.040 & .12367 & $.25650^{*}$ & $\mathrm{p} 6$ & \\
.147 & .12053 & .17539 & $\mathrm{p} 1$ & $\mathrm{P} 6$ \\
.190 & .11634 & .15299 & $\mathrm{p} 2$ & \\
.838 & .13799 & .02827 & $\mathrm{p} 3$ & \\
.309 & .11634 & .11880 & $\mathrm{p} 4$ & \\
.040 & .12367 & $-.25650^{*}$ & $\mathrm{p} 5$ & \\
\hline
\end{tabular}


Because the significance level of the test for all variables except memory is below 5\% error level, it can be said that the degree of identity of sense of attachment to place and satisfaction is varied in different areas. However, the degree of memory in different areas does not differ from each other. To investigate whether identity, belonging, attachment to place and satisfaction are different in each regions, LSD test is used. According to the above table, it can be concluded that the degree of identity in areas P1 with P5 $\leq$ P2 with P5 P3 with P5 P4 with P5 P6 and $\mathrm{P} 5$ are significantly different from each other.

\section{REFERENCES}

1. Bonnes, M., \& Secchiaroli, G. 1995.Environmental Psychology: A Psycho-social Introduction (C. Montagna, Trans.). Sage Publications, Inc.

2. GS, Manor O., 1998. Social Ties, Environmental Perception, and Local Attachment. Environment and Behavior 30: 504-519.

3. Hauge, A. L. \& Kolstad, A. (2007). Dwelling as an expression of identity: A comparative study among residents in high-priced and low-priced neighbourhoods in Norway. Housing, Theory \& Society, 24, 272-292.

4. A, Shinar \& S.Y, C Chicago., 1985. Chicago of University; WorksNet Friendship and Neighborhoods.

5. Rapoport, Amos, A. House Form and Culture, Englewood Cliffs, CA: Prentice Hall, 1969.

6. Rapoport, Amos, Culture Architecture and design, Locke science publishing company, Inc, Chicago, USA, 2005.

7. Zukin, S. 1995. The Cultures of Cities. Cambridge, MA: Blackwell.

8. Yung-Jaan Lee., Subjective quality of life measurement in Taipei., Building and Environment 43(7):1205-1215 · July 2008.

9. Povar Schneider., Human Sexuality and the Handicapped, First Published: March 1976.

10. Ghasemi Esfahani, Morvarid, Where are we from (identity in residential contexts), Roozane Publications, 2004.

11. Pakzad, J. " Identity \& This Same with Space ", Journal of Soffeh. (21 \& 22). 1995, pp. 100-106.

12. Farah Habib, Vahideh Hodjati and Hamed Moztarzadeh., The Concept of Neighborhood and its Constituent Elements in the Context of Traditional Neighborhoods in Iran., Advances in Environmental Biology Journal. 7(9):2270-2278 • September 2013.

13. Arbab Jolfayi, Arash, Philosophical and Psychological Foundations of Space Perception ؛ Collected and Translated Papers, Khak Publishing, 2000.

14.Zahra Khodaee, Mojtaba Rafiean and Seyed Reza Salehi Amiri., Effective Factors on Youth Satisfaction From Public Urban Spaces in Tehran. Residential Treatment for Children \& Youth Journal., February 2015.Mir Moqtadaie, Mehta, Physical Identity of the City, Building and Housing Research Center, 2006.

15. Sommer, R., 1969. Personal Space: The Behavioral Basis of Design. Englewood Cliffs, NJ: PrenticeHall.

16. M. Carmona, T. Heath, T. Oc, S.T. Tiesdell Public Places Urban Spaces: The Dimensions of Urban Design, Architectural Press, London, 2003.

17.Al-Naim, Mashary; Identity in Transitional Context: Open_Ended Local Architecture in Sudi Arabia; International Jornal of Architectural Research, Vol. 2, 2008.

18. Cassatella, Claudia and Peano, Attilia, Landscape Indicators book, Assessing and Monitoring Landscape Quality, Springer Netherlands, 2011.

19. Michele J. Gelfand, Chi-yue Chiu, Ying-yi Hong., Advances in Culture and Psychology: Volume 2, oxford university press. 2012.

20.Jian, Ge., Kazunori, Hokaob. Applying the Methods of Image Evaluation and Spatial Analysis to Study the Sound Environment of Urban Street Areas, Journal of Environmental Psychology, Volume 25, Issue 4, December 2005, Pages 455-466.

21. Hee-Jung Jun and Hyun Jeong., Residential Satisfaction Among Public Housing Residents Living in Social-Mix Housing Complexes: The Case of the Seoul Metropolitan Area, Korea. Urban Policy and Research Journal. May 2018.

22.M Bonaiuto. 2002. Local Identity Processes and Environmental Attitudes in Land use Changes: The Case of Natural Protected Areas, Journal of Economic Psychology 23(5):631-653. October 2002. 
23.Williams, D.R., And J.W. Roggenbuck. 1989. Measuring Place Attachment: Some Preliminary Results. P. 32 In Abstracts of the 1989 Symp. On Leisure Research. National Recreation and Park Assoc., Alexandria, Va.

24.Warzecha, C.A., and D.W. Lime. 2001. Place Attachment Incanyonlands National Park: Visitors' Assessments of Settingattributes on the Colorado And Green Rivers. J. Park Rec.Admin. 19:59-78.

25.Jerry J. Vaske \& Katherine C. Kobrin. Place Attachment and Environmentally Responsible Behavior, The Journal of Environmental Education 32(4):16-21. January 2001.

26.Clare Twigger-Ross and Marino Bonaiuto., Identity theories and environmental psychology, psycholocal theories for envoirenmental issues jornal, January 2003.

27.Williams, D.R., M.E. Patterson, J.W. Roggenbuck, and A.E. Watson. 1992. Beyond The Commodity Metaphor: Examining Emotional and Symbolic Attachment to Place. Leisure Sci. 14:29-46.

28.Daniel R. Williams and Norman Mcintyre., Where heart and home reside: Changing constructions of place and identity, January 2000. Conference: Trends 2000: Shaping the future, At East Lansing, MI.

29.Stokols, D., \&Shumaker, S. A. (1981). People in places: A transactional view of settings.In Harvey, J. H. (Ed.).Cognition social behaviour and the environment.(pp.441-488)Hillsdale, NJ: Lawrence Erlbaum Assoc.

30.Bricker \& Kerstetter., Level of Specialization and Place Attachment: An Exploratory Study of Whitewater Recreationists, Leisure Sciences, 22:233-257, 2000.

31. M.J. Rosenberg, C.I. Hovland, Cognitive, affective, and behavioral components of attitudes, Yale University Press, Yale studies in attitude and communication, 1960.

32.Williams, Daniel R.; Vaske, Jerry J. 2003. The Measurement of Place Attachment: Validity and Generalizability of a Psychometric Approach. Forest Science. 49(6): 830-840).

33.Edward Relph., Place and Placelessness, Publisher Pion, 2008.
34.Proshansky Et Al., 1983. Journal of Environmental Psychology (1983) 3, 57-83 PlaceIdentity: Physical World Socialization of the Self. Graduate School And University Center The City University of New York, U.S.A.

35.Giuliani, M. V., \& Feldman, R. (1993). Place attachment in a developmental and cultural context. Journal of Environmental Psychology, 13, 267-274.

36.Feldman, R. M. (1990). Settlement Identity: Psychological Bonds with Home Places in a Mobile Society. Environment and Behavior, 22, 183-229.

37. Kelly S. Bricker and Deborah Kerstetter., Level of Specialization and Place Attachment: An Exploratory Study of Whitewater Recreationists. October 2000. Leisure Sciences journal 22(4).

38.Williams, D.R., Roggenbuck, J.W., 1989. Measuring Place Attachment: Some Preliminary Results Abstracts of the 1989 Leisure Research Symposium.

39.Gerard T Kyle et al., Effects of Place Attachment on Users' Perceptions of Social and Environmental Conditions in a Natural Setting. Journal of Environmental Psychology 24(2):213-225. June 2004.

40.Jerry J. Vaske and Katherine C. Kobrin. Place Attachment and Environmentally Responsible Behavior, The Journal of Environmental Education, Volume 32, 2001 - Issue 4, 2001.

41.Daneshpour, Seyed Abdollhad., Recognizing the Concept of Identity in Urban Public Space (Street) Case Study: Tehran Enghelab Street; PhD dissertation, School of Fine Arts, Tehran University, 2000. 